\title{
Uso de revestimento de fécula de mandioca e lactato de cálcio em mamão minimamente processado
}

\author{
Application of starch manioc coating and calcium lactate in fresh-cut of papaya \\ Aplicación de cobertura de almidón de mandioca y lactato de calcio en papaya recién cortada
}

Recebido: 17/08/2021 | Revisado: 26/08/2021 | Aceito: 02/09/2021 | Publicado: 04/09/2021
Marcelo Augusto Gutierez Carnelossi
ORCID: https://orcid.org/0000-0002-2961-5557 Universidade Federal de Sergipe, Brasil E-mail: magcarnelossi@gmail.com
Paula Tais Maia Santos
ORCID: https://orcid.org/0000-0003-1544-1354 Universidade Federal de Sergipe, Brasil
E-mail: paula.tais.ms@gmail.com
Patrícia Beltrão Lessa Constant
ORCID: https://orcid.org/0000-0001-7095-940X Universidade Federal de Sergipe, Brasil E-mail: pblconstant@academico.ufs.br
Glenda Barros Matos
ORCID: https://orcid.org/0000-0002-0085-4386 Universidade Federal de Sergipe, Brasil
E-mail: glendabmatos@yahoo.com
Marcílio Nunes Moreira
ORCID: https://orcid.org/0000-0001-5958-8302 Universidade Federal de Sergipe, Brasil
E-mail:marcilio10@gmail.com
Raíssa Ingrid Santana Araujo Costa
ORCID: https://orcid.org/0000-0002-6497-2111
Universidade Federal de Sergipe, Brasil
E-mail: rai_ingrid@hotmail.com
Alysson Caetano Soares
ORCID: https://orcid.org/0000-0002-0448-6998 Universidade Federal de Sergipe, Brasil
E-mail: alyssoncs1@hotmail.com
Lucas de Souza Santos
ORCID: https://orcid.org/0000-0002-6639-8379 Universidade Federal de Sergipe, Brasil E-mail: lucas.uni.souza@ outlook.com
Aline Andrade Reis
ORCID: https://orcid.org/0000-0001-7101-1354 Universidade Federal de Sergipe, Brasil E-mail: lineandradereis@gmail.com
Patrícia Nogueira Matos
ORCID: https://orcid.org/0000-0001-6090-8318 Universidade Federal de Sergipe, Brasil E-mail: apatynogueira@hotmail.com
Paulo Roberto Gagliardi
ORCID: https://orcid.org/0000-0002-9394-8604 Universidade Federal de Sergipe, Brasil
E-mail: prgagli@academico.ufs.br

\section{Resumo}

O mamão após o processamento mínimo pode apresentar algumas alterações físico-químicas e bioquímicas em resposta ao processamento. No entanto, algumas técnicas de pós-colheita, tais como, o uso de revestimentos comestíveis e utilização de lactato de cálcio podem ser empregados de forma a minimizar essas alterações e prolongar a vida de útil do produto. O presente trabalho teve como objetivo verificar a eficiência da aplicação de lactato de cálcio (6\%) e revestimento comestível a base de fécula de mandioca (3\%), na manutenção da firmeza e na qualidade de mamão formosa minimamente processado. A cada 4 dias foram retiradas amostras para análise de perda de massa, cor, $\mathrm{pH}$, acidez total titulável, sólidos solúveis totais, teores de ácido ascórbico e firmeza (N). Verificou-se que a partir do 8 dia os teores de vitamina $\mathrm{C}$ do mamão minimamente processado foram menores nas amostras tratadas com cálcio ou revestidas quando comparadas com o controle. $\mathrm{O}$ uso de revestimento de fécula de mandioca não foi eficaz na 
manutenção das características físico-químicas analisadas. Verificou-se também que mamão minimamente processado tratado com lactato de cálcio apresentaram significativamente ( $\mathrm{p}<0,05 \%)$ manutenção da coloração, acidez e pH quando comparado com frutos controle ou revestidos.

Palavras-chave: Carica papaya L.; Pós-colheita; Revestimento comestível.

\begin{abstract}
Papaya after minimal processing may present some physicochemical and biochemical changes in response to processing. However, some post-harvest techniques, such as the use of edible toppings and the use of calcium lactate, can be used in order to minimize these changes and prolong the shelf life of the product. This study aimed to verify the efficiency of the application of calcium lactate (6\%) and cassava starch-based edible coating (3\%) in maintaining the firmness and quality of fresh-cut papaya. Every 4 days, samples were taken for analysis of mass loss, color, $\mathrm{pH}$, total titratable acidity, total soluble solids, ascorbic acid content and firmness $(\mathrm{N})$. It was found that from the 8th day, the vitamin $\mathrm{C}$ contents of freshly processed papaya were lower in samples treated with calcium or coated when compared to the control. The use of cassava starch coating was not effective in maintaining the physicochemical characteristics analyzed. It was also found that the minimally processed papaya treated with calcium lactate showed significant maintenance ( $\mathrm{p}<0.05 \%)$ of color, acidity and $\mathrm{pH}$ when compared to control or coated fruits.
\end{abstract}

Keywords: Carica papaya L.; Post-harvest; Edible coating.

\title{
Resumen
}

La papaya después de un procesamiento mínimo puede presentar algunos cambios fisicoquímicos y bioquímicos en respuesta al procesamiento. Sin embargo, se pueden utilizar algunas técnicas de poscosecha, como el uso de revestimientos comestibles y el uso de lactato de calcio, para minimizar estos cambios y prolongar la vida útil del producto. Este estudio tuvo como objetivo verificar la eficiencia de la aplicación de lactato de calcio (6\%) y cobertura comestible a base de almidón de yuca (3\%) para mantener la firmeza y calidad de la papaya recién cortada. Cada 4 días se tomaron muestras para análisis de pérdida de masa, color, $\mathrm{pH}$, acidez total titulable, sólidos solubles totales, contenido de ácido ascórbico y firmeza $(\mathrm{N})$. Se encontró que a partir del octavo día en adelante, el contenido de vitamina $\mathrm{C}$ de la papaya recién procesada fue menor en las muestras tratadas con calcio o recubiertas en comparación con el control. El uso de cobertura de almidón de yuca no resultó eficaz para mantener las características físicoquímicas analizadas. También se encontró que la papaya mínimamente procesada tratada con lactato de calcio mostró un mantenimiento significativo $(\mathrm{p}<0.05 \%$ ) del color, la acidez y el $\mathrm{pH}$ en comparación con las frutas de control o recubiertas.

Palabras clave: Carica papaya L.; Postcosecha; Recubrimiento comestible.

\section{Introdução}

O mamão (Carica papaya L.) é uma das frutas tropicais que ocupa um lugar de destaque no comércio, estando entre os furtos mais consumidos no Brasil (Revista da Fruta, 2016). Caracteriza-se por ser um fruto carnoso com características sensoriais, químicas e digestivas de grande apreço comercial. Sendo um fruto climatérico, apresenta alta atividade metabólica, perda de água, além de apresentar um aumento considerável na taxa de respiração e produção de etileno após ser retirado da planta-mãe (Oliveira, Sasaki, Nepomuceno \& Silva, 2018; Scapin, Steffen, Bacarol \&Adams, 2018). Quando maduro, apresenta alterações na coloração, aroma, sabor e textura devido às transformações bioquímicas, como mudanças nos teores de pigmentos, compostos voláteis, ácidos orgânicos e carboidratos (Santana, Matsuura \& Cardoso, 2004; Moretti, 2007).

Dentro da pós-colheita são empregadas técnicas com a finalidade de transformar o produto colhido em um produto de consumo imediato, sendo um destes o processamento mínimo (PM). Este consiste em diversas operações que eliminam partes não comestíveis, como casca, talos e sementes, seguida do preparo em tamanhos menores e deixam os frutos prontos para consumo imediato, sem que os mesmos percam a condição de produto fresco, e apresentem qualidade e garantia de sanidade (Ma, Zhang, Bhandari \& Gao, 2017; Oliveira, Abadias, Usall \& Torres, 2015). No entanto, o emprego do processamento mínimo em frutos pode diminuir a vida útil dos alimentos, quando comparado com o produto intacto, devido as reações bioquímicas que ocorrem nos tecidos cortados, tais como: aumento na taxa respiratória e na produção do etileno (Batista \& Borges 2013). Para minimizar estes efeitos, pode ser aplicado revestimentos comestíveis, agentes antimicrobianos, atmosferas modificadas, entre outros, os quais auxiliam na preservação dos alimentos, mantem a qualidade nutritiva e as características organolépticas dos frutos, além de aumentar a vida de prateleira (Cortez-Veja, Piotrowicz, Prentice, Borges, 2013). 
Os revestimentos em frutos minimamente processados caracterizam-se pela formação de uma película capaz de inibir/reduzir a difusão de umidade e trocas gasosas, tendo como maior foco a redução da penetração do oxigênio, necessário para síntese de etileno, o qual pode levar a maturação do fruto (Chitarra \& Chitarra, 2005; Assis \& Brito, 2014).

Outra técnica utilizada na conservação do mamão é a adição de sais de cálcio, que também podem ser aplicados como coadjuvantes na tecnologia de fabricação de alimentos (Aslam, Inam-Ur-Raheem, Zanoor \& Shahid, 2018). Esta técnica consiste na imersão da matriz alimentar numa solução líquida e, em seguida, na aplicação da pressão de vácuo por um determinado período para garantir que o ar retido no material poroso seja removido (Caudal et al. 2016).

Assim sendo, o presente trabalho teve como objetivo utilizar sais de cálcio e revestimento comestível a base de fécula de mandioca como agentes de manutenção da firmeza e preservação das características físico-químicas e bioquímicas do mamão formosa minimamente processado.

\section{Materiais e Métodos}

O trabalho foi desenvolvido, no Laboratório de Frutas e Hortaliças, localizado no Departamento de Tecnologia de Alimentos (DTA) e no Laboratório de Flavor (Laf), da Universidade Federal de Sergipe (UFS). O mamão formosa (Carica papaya) foi adquirido CEASA (Centro de Abastecimento do Estado de Sergipe) - situada na cidade de Aracaju/SE. De acordo com Pereira et al. (2018), o estudo é classificado como laboratorial com abordagem quantitativa.

As frutas foram selecionadas quanto a coloração da casca, no estádio de maturação do subgrupo 4, contendo de 50 a 75\% da casca amarelada, como ilustrado na cartilha de classificação do mamão (CEAGESP, 2017).

O processamento foi realizado seguindo-se as boas práticas de fabricação $(\mathrm{BPF})$, em ambiente refrigerado $\left(19 \pm 2^{\circ} \mathrm{C}\right)$. Depois de adequadamente higienizados, a polpa do mamão foi cortada em formato esférico (com diâmetro de aproximadamente $21 \mathrm{~mm}$ e peso em torno de $6 \mathrm{~g}$ ) e enxaguadas emergindo-as em água clorada $3 \mathrm{ppm}$ de cloro ativo a $5^{\circ} \mathrm{C}$.

As amostras de mamão minimamente processado do tratamento controlem foram embalados após a drenagem. Realizaram-se as demais etapas separando as amostras em 3 tratamento: infusão do lactato cálcio $6 \%$, revestimento de fécula de mandioca $5 \%$ e infusão do lactato de cálcio $6 \%$ revestido com solução de fécula de mandioca $5 \%$.

A infusão dos sais de cálcio foi preparada uma solução de $6 \%$ de lactato de cálcio, com o auxílio de um dessecador e uma bomba a vácuo, à pressão de 40kPa (300 mmHg) por 10 minutos, seguidas de drenagem, por 1 minuto (Silva, Silva, Silva, Waldan \& Oliveira, 2015; Shinagawa, 2009). A aplicação da fécula de mandioca foi procedida com o preparo da solução a 3\% e as esferas de mamão foram imersas por 2 minutos e drenadas posteriormente por 1 minuto (Trigo et al., 2012; Caudal et al., 2016).

Os mamões minimamente processados foram acondicionados em potes de polipropileno, com tampa de mesmo material. Estes foram armazenados em um expositor vertical, com temperatura a $5 \pm 1{ }^{\circ} \mathrm{C}$ durante o período de 12 dias. A cada quatro dias foram retiradas amostras para a realização das análises, sendo estas: análise de cor, sólidos solúveis, potencial hidrogeniônico, perda de massa, ácido ascórbico, firmeza.

\section{Resultados e Discussão}

\subsection{Análise de cor}

As características determinantes da qualidade de um produto são consideradas internas e externas. Os primeiros referem-se às características organolépticas; os segundos são aqueles relacionados à cor, forma e em geral aos outros fatores sensoriais (Acevedo, 2008). A Figura 1 apresenta a coordenada colorimétrica L (luminosidade) para os tratamentos ao longo do armazenamento. 
Figura 1. Luminosidade ("L") de mamão minimamente processado ao longo do tempo de armazenamento com diferentes tratamentos

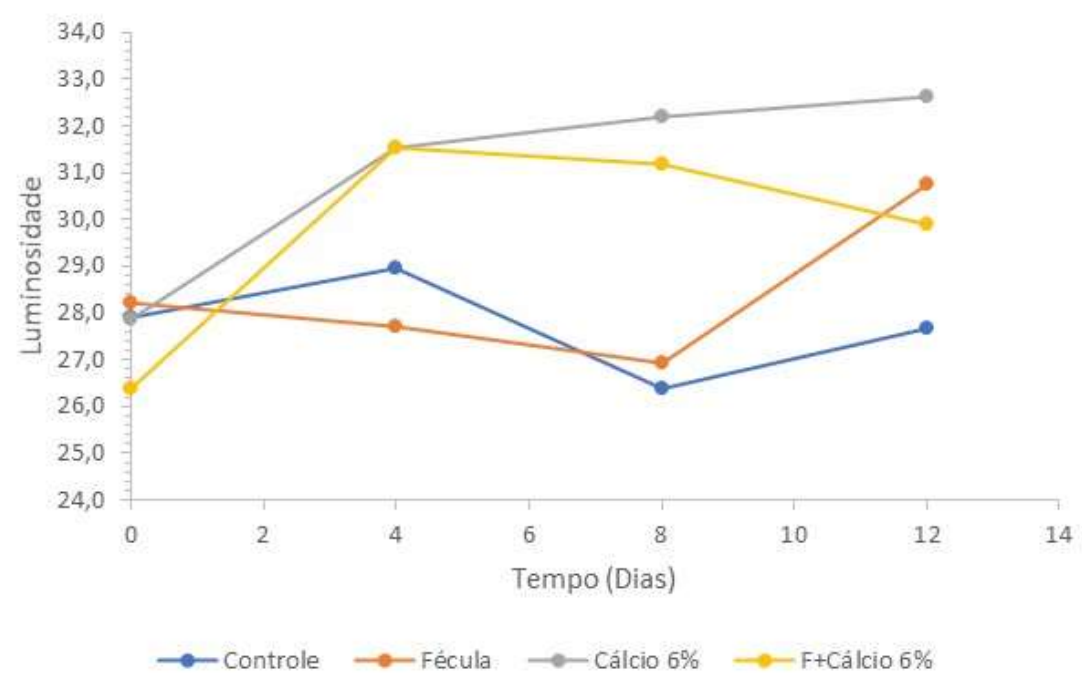

Fonte: Autores (2021).

O parâmetro " $L$ " das amostras cálcio e fécula+cálcio, destacando-se os valores a partir quarto dia, mostrando que a aplicação do lactato de cálcio contribuiu para a manutenção deste parâmetro. Nestas amostras, os valores de "L", com índices mais elevado que a amostra controle e fécula, tiveram suas médias entre $29,9^{\circ}$ e $33,0^{\circ}$, no oitavo e décimo segundo dia (Figura 1). Os sais de cálcio proporcionam uma estabilização da estrutura celular, não liberando substâncias responsáveis por reações bioquímicas que ocasionam mudanças da luminosidade. Miguel, Dias e Spoto (2007) aplicaram cloreto de cálcio em melancias minimamente processadas, tendo como resultado uma manutenção da coloração, no parâmetro L, por 6 dias de armazenamento.

A amostra controle no $4^{\circ}$ para o $12^{\circ}$ dia decresceu os índices de luminosidade, indicando a ocorrência do escurecimento do fruto. A amostra contendo apenas o revestimento de fécula teve também o decréscimo dos valores de luminosidade, entre o $4^{\circ}$ e $8^{\circ}$ dia de armazenamento, indicando o escurecimento.

A Figura 2 apresenta a coordenada $\mathrm{h}$ (tonalidade) para os tratamentos ao longo do armazenamento. 
Figura 2. Ângulo hue (" $h$ *”) de mamão minimamente processado ao longo do tempo de armazenamento com diferentes tratamentos

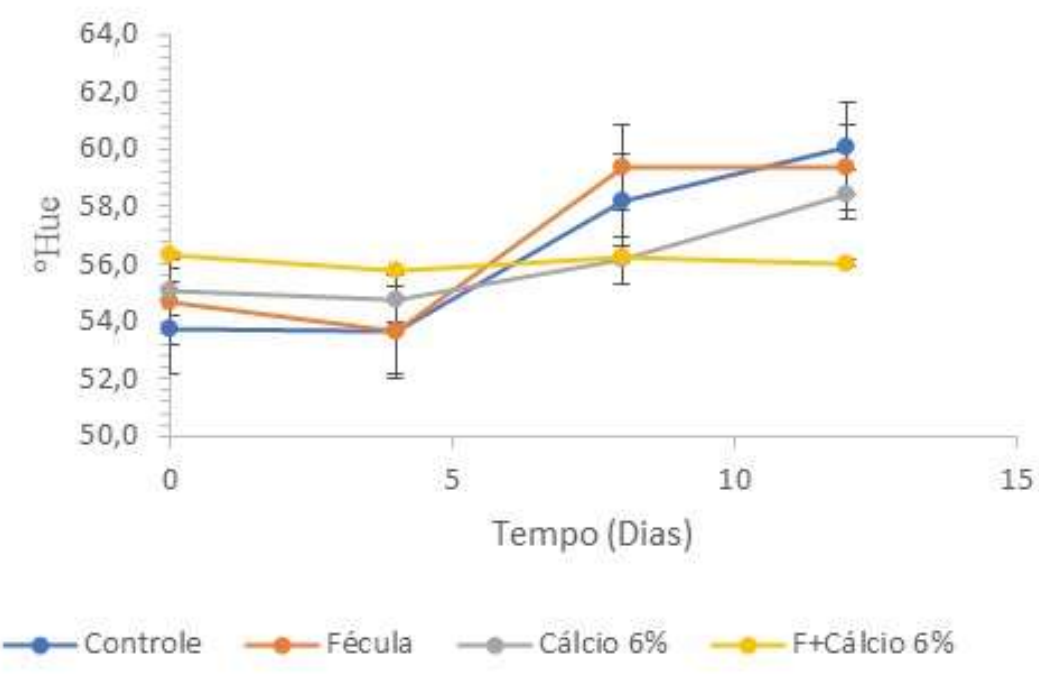

Fonte: Autores (2021).

Analisando-se o ângulo "hue" (Figura 7), verificou-se que o tratamento fécula de mandioca não interfere significativamente $(\mathrm{p}<0,05)$ na manutenção da coloração do fruto, tendo seus valores entre $54,7^{\circ}$ e $59,8^{\circ}$, semelhantes ao da amostra controle, que compreenderam entre $53,8^{\circ}$ e 60,0 . Rivera-Lopez et al. (2005) também relataram ângulos de matiz iniciais de $53 \pm 2,5^{\circ} \mathrm{h}$, cujos cubos e fatias de mamão processados mantiveram sua cor natural amarela / vermelha durante 18 dias de armazenamento.

A aplicação do lactato de cálcio, contribuiu para o controle da coloração, mantendo uma faixa de $55^{\circ} \leq \mathrm{h}^{*} \leq 58,4^{\circ} \mathrm{em}$ todo o tempo de armazenamento. O controle da coloração é um aspecto positivo, uma vez que a tendência com o processo de maturação do mamão é elevar seus valores do ${ }^{\circ}$ hue, apresentando uma coloração mais alaranjada, como é verificado na Figura 2 no tratamento controle, podendo indicar a degradação dos carotenoides (Oliveira, Berberte, Pereira, Vieira, Carlesso, 2011).

\subsection{Sólidos Solúveis}

O teor de sólidos solúveis totais (SST) (Figura 3) da amostra controle variou de 8,8 a 11,60 Brix, sendo inferiores aos valores médios 13,30 Brix e 12,00 Brix, obtidos por Viegas (1992) para as cultivares 'Sunrise-Solo' e grupo 'Formosa', respectivamente. Fioravanço, Paiva, Carvalho e Manica (1994) analisaram frutos do grupo 'Solo' e encontraram valores de SST oscilando entre 8,68 e 11,66 ${ }^{\circ}$ Brix. Por ser um fruto que apresenta quantidades/traços de amido na polpa, a variação no teor de SS após a colheita é muito pequena e, quando ocorre, é resultado da degradação da parede celular, que aumenta a liberação de pectina solúvel nos espaços intercelulares, contribuindo com um ligeiro aumento no teor de SS (Yao et al., 2014). 
Figura 3. Teores de sólidos solúveis de mamão minimamente processado ao longo do tempo de armazenamento com diferentes tratamentos.

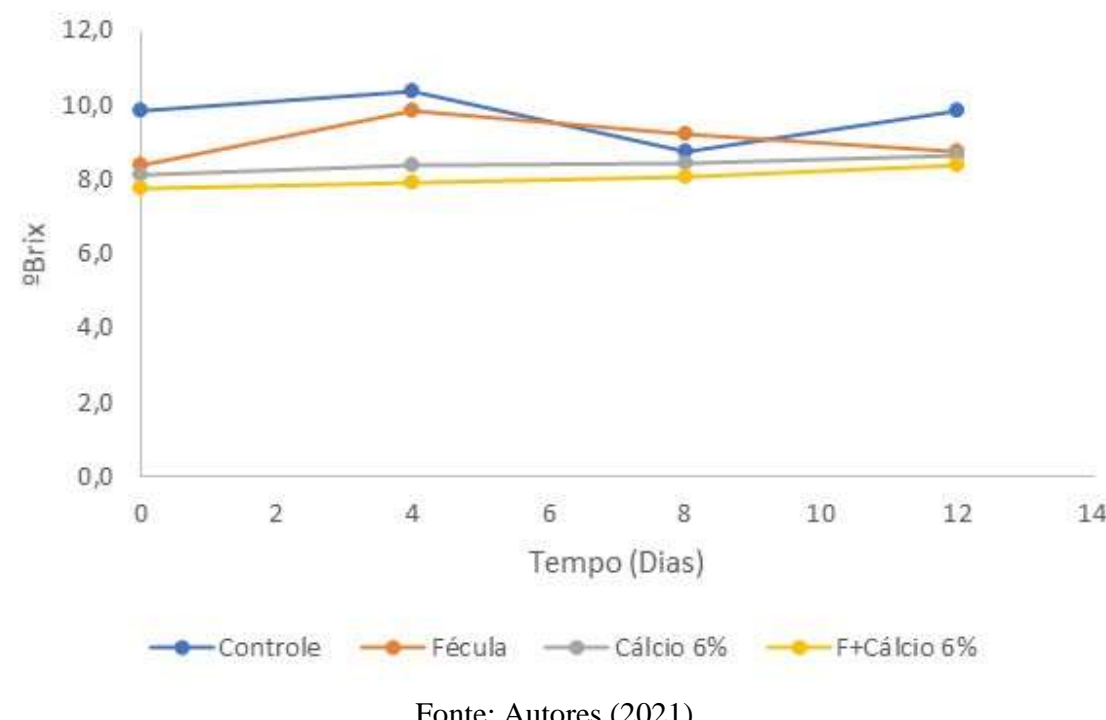

Nos tratamentos fécula, cálcio $6 \%$ e Fécula+Cálcio $6 \%$, não diferiram entre si $(\mathrm{p}<0,05)$ no decorrer do tempo de armazenamento. Apenas no primeiro dia de análise as amostras contendo lactato de cálcio diferiu de forma significativa $(\mathrm{p}<0,05)$ das demais amostras, tendo seus valores compreendidos em 10,47 ${ }^{\circ}$ Brix para a amostra lactato $6 \%$ e $10,70{ }^{\circ} \mathrm{Brix}$ para a amostra fácula+lactato $6 \%$. Silva et al (2015) aplicaram cloreto de cálcio como agente de manutenção de firmeza em manga minimamente processada e verificaram que os teores sólidos solúveis também não apresentaram diferença significativa $(\mathrm{p}<0,05)$. Apesar desse fato, foi possível verificar que os valores de sólidos solúveis presentes nas amostras tratadas com lactato de cálcio, tendo seus valores compreendidos entre 6,9 e $9,3^{\circ}$ Brix, no decorrer dos dias de armazenamento. Aslam et al (2018) estudaram o efeito integrado do ácido ascórbico, do ácido cítrico e do lactato de cálcio na qualidade e na vida útil dos cubos de mamão e tiveram como resultado menores valores de sólidos solúveis nas amostras contendo a maior concentração de lactato de cálcio, $2,4 \%$.

\subsection{Acidez Titulável}

Houve aumento nos teores de ácido cítrico nas amostras controle e fécula em 3\% (Figura 4), nos tempos 0 e 8, de 6,99 a 15,34\% de ácido cítrico e 7,02 a 14,01 \% de ácido cítrico, respectivamente. Estes resultados podem ser decorrentes das reações fisiológicas e bioquímicas da fase de maturação, induzindo a formação de alguns tipos de ácidos (Cortez-Veja et al., 2013). O aumento da acidez é dado pela formação do ácido galacturônico no processo de degradação da parede celular durante o amadurecimento do mamão, com isso, é de se esperar que a amostra controle aumente sua taxa de ácido cítrico no decorrer do armazenamento (Costa OSTA \& Balbino, 2002). 
Figura 4. Acidez Titulável de mamão minimamente processado ao longo do tempo de armazenamento com diferentes tratamentos.

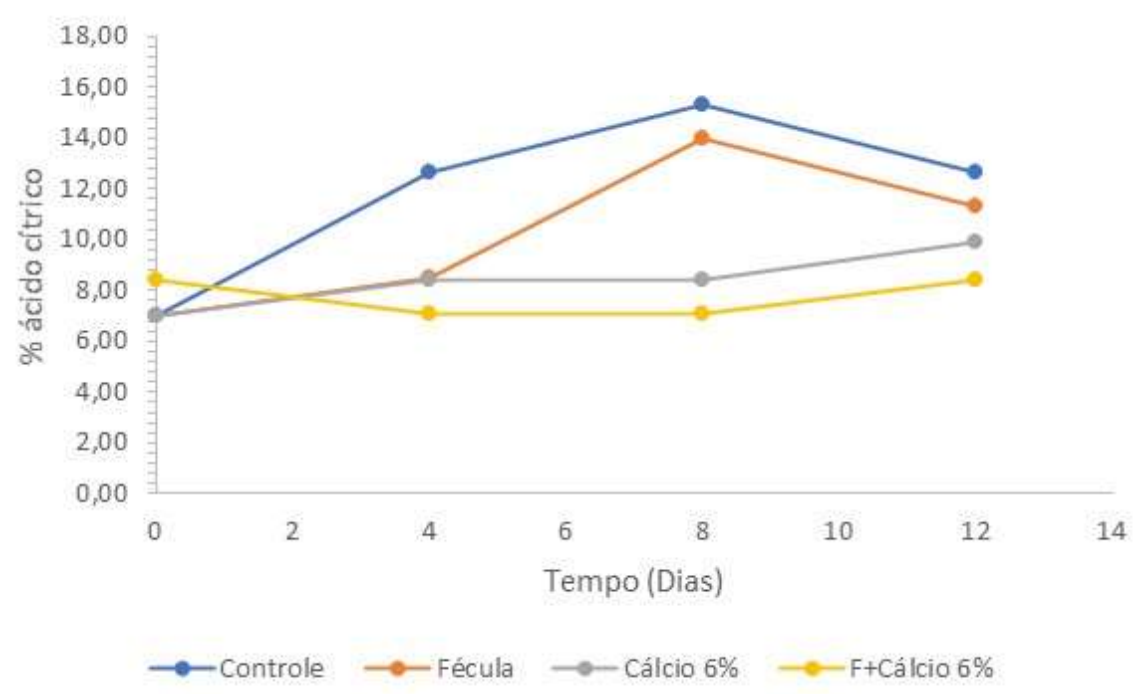

Fonte: Autores (2021).

A aplicação de lactato de cálcio apresentou (Figura 3) uma resposta positiva na manutenção da acidez do fruto, prolongando suas características sensoriais neste quesito, permanecendo com o teor de ácido cítrico entre 7\% e 9\%, o que interfere também no $\mathrm{pH}$ do fruto, desacelerando a velocidade de amadurecimento. Segundo Draetta et al. (1975), o aumento na acidez na polpa dos frutos de mamoeiro, ao longo do seu amadurecimento, está vinculado à formação de ácido galacturônico proveniente da hidrólise da pectina pela enzima pectina metilesterase.

\subsection{Potencial Hidrogeniônico}

Os resultados de $\mathrm{pH}$ (Figura 5) obtidos no tratamento controle tiveram diferença significativa $(\mathrm{p}<0,05)$ com o passar dos dias de armazenamento, iniciando com o pH em 6,15 no tempo 0 e finalizando com 5,60 no tempo 12 . Santana el al. (2004) descrevem que a taxa de ácidos orgânicos no mamão é baixa e sua polpa está na faixa de pH entre 4,5 a 6,0, estando de acordo com as médias experimentais que foram obtidas.

Figura 5. Potencial Hidrogeniônico de mamão minimamente processado ao longo do tempo de armazenamento com diferentes tratamentos.

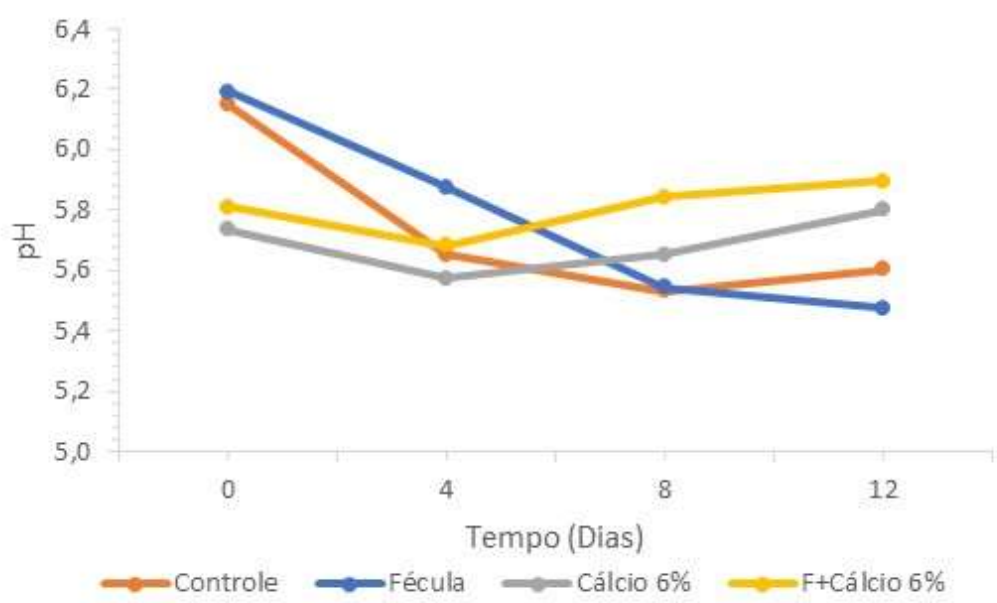

Fonte: Autores (2021). 
$\mathrm{Na}$ amostra controle, entre o primeiro e oitavo dia, houve o aumento da acidez do mamão minimante processado, tendo seus valores compreendidos em 7,00 e 15,34 \% de ácido cítrico, e com isso a diminuição do pH, de 6,15 para 5,53. O mesmo ocorreu com a amostra fécula, onde seus teores de ácido cítrico encontram-se de 7,00 a 14,01\% e pH caindo de 6,19 para 5,54

Santana et al. (2004) verificaram e correlacionaram as alterações de pH e acidez titulável de 12 genótipos de mamão com coloração da casca $100 \%$ amarela, pelo período de dois anos. Para o primeiro e o segundo anos, respectivamente, obtiveram os seguintes valores: $\mathrm{pH}$, variando na faixa de 5,19 a 5,59 e 4,91 a 5,89); acidez titulável total, em torno de 0,04 a 0,13g ácido cítrico/100g amostra e 0,07 a 0,16g ácido cítrico/100g amostra.

Correlacionando os resultados com a aplicação do lactato de cálcio, houve o controle do teor de ácido cítrico, devido à manutenção da parede celular ocasionada pelo lactato de cálcio, refletindo no potencial hidrogeniônico de mamão minimamente processado, tendo este um comportamento diferente da amostra controle e fécula.

\subsection{Perda de Massa}

A Figura 6 apresenta a perda de massa de mamão minimamente processado ao longo do tempo de armazenamento com diferentes tratamentos. Todos os frutos mostraram perda de massa fresca progressiva durante o período de armazenamento, tendo diferença significativa $(\mathrm{p}<0,05)$ apenas nas amostras contendo o revestimento à base de fécula de mandioca. Essa diferença pode ser explicada devido à retrogradação do amido da solução filmogênica, levando em consideração à baixa temperatura de armazenamento, $5 \pm 1^{\circ} \mathrm{C}$.

A aplicação do lactato de cálcio não diferiu significativamente $(\mathrm{p}<0,05)$ com relação à amostra controle, podendo ser devido à concentração do lactato de cálcio aplicada, uma vez que o excesso de sais de cálcio na solução aplicados sobre o fruto pode causar desidratação dos tecidos (Azzolini, Jacomino \& Bron, 2004). Werner, Oliveira Jr., Bona, Cavati \& Gomes (2009) verificaram que as menores perdas de massa fresca foram observadas nos frutos tratados com solução de $\mathrm{CaCl}_{2}$ a $1 \%$.

Figura 6. Perda de massa de mamão minimamente processado ao longo do tempo de armazenamento com diferentes tratamentos.

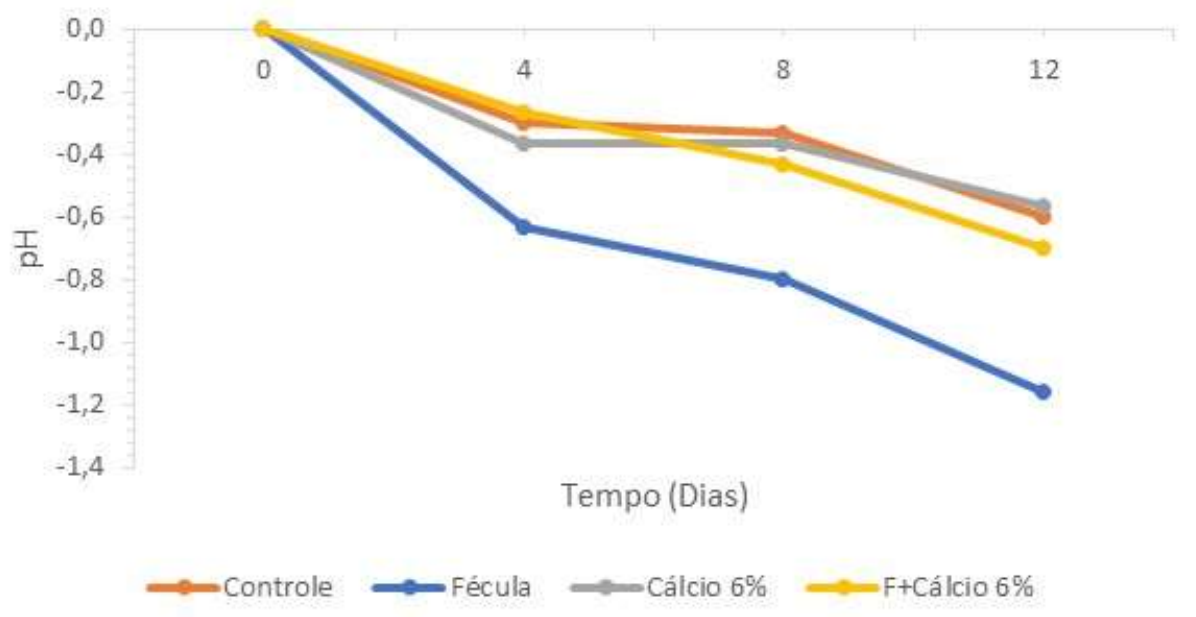

Fonte: Autores (2021).

\section{6 Ácido Ascórbico}

Os valores de vitamina $\mathrm{C}$ não diferiram significativamente $(\mathrm{p}<0,05)$ ao decorrer do tempo e diferenciando os tratamentos. Porém, verificou-se redução dos valores de ácido ascórbico nas amostras contento lactato de cálcio 6\%, em 
comparação com os tratamentos controle e fécula, com média de diferença de 13,0 mgAA/100g de amostra. Tais reduções podem estar correlacionadas com o menor fornecimento de intermediários, produzidos pela oxidação de açúcares para a produção de L-galactona-1,4-lactona, que é o percussor imediato na síntese de ácido ascórbico (Silva et al., 2015).

De maneira geral, teor deste ácido nas frutas e hortaliças durante o amadurecimento decresce, levando em consideração seu estádio de maturação e cultivar (Cheftel \& Cheftel, 1992). No mamão o nível de ácido ascórbico aumenta gradualmente durante o amadurecimento, alcançando valor máximo de 55mg/100g (Giannoni, 2004).

\subsection{Análise da Firmeza}

O decréscimo da firmeza no processo de maturação do fruto, foi verificado na amostra controle e fécula (Figura 7). Assim sendo, a fécula de mandioca pouco contribui para a manutenção da firmeza do mamão minimamente processado, em comparação com a amostra controle, tendo suas diferenças no oitavo e décimo segundo dia de $0,33 \mathrm{~N}$ e $0,90 \mathrm{~N}$, respectivamente.

Figura 7. Firmeza em mamão minimamente processado nos diferentes tratamentos, estocados a $5 \pm 1^{\circ} \mathrm{C}$ por 12 dias.
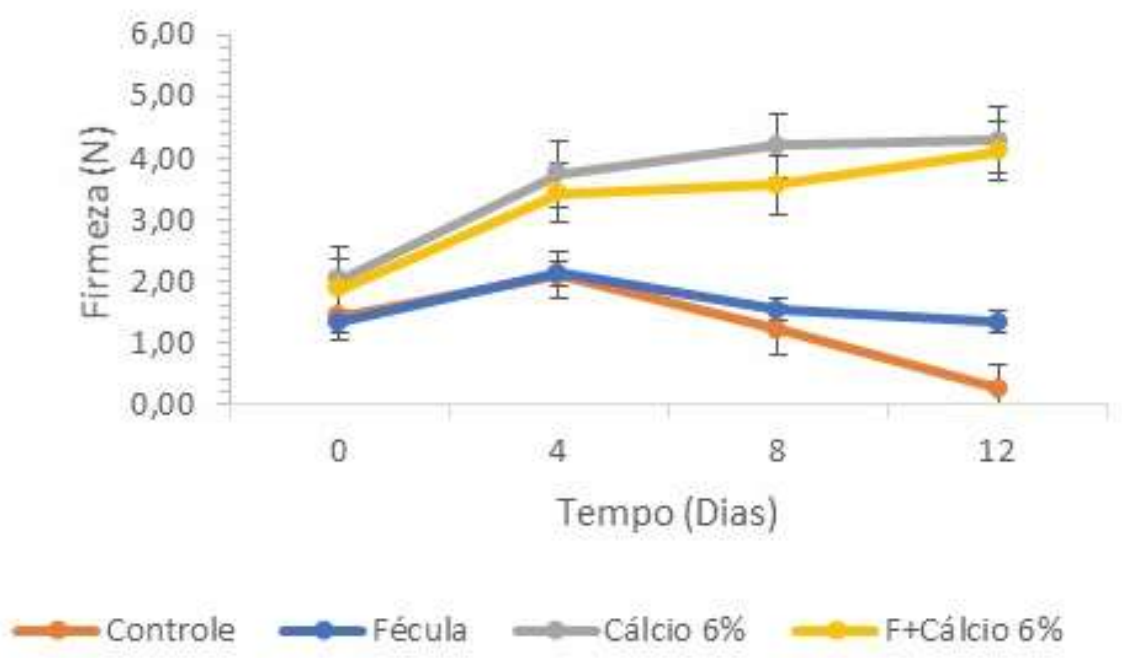

Fonte: Autores (2021).

A perda de firmeza é um processo natural maturação do fruto, devido ao aumento da atividade enzimática na degradação da pectina presente nas paredes celulares (Silva et al., 2015). Nunes, Neto, Nascimento, Oliveira \& Mesquita (2017) verificaram que a aplicação de fécula de mandioca em $2 \%$ e $6 \%$ em mamão formosa resultou em decréscimo da firmeza com o passar do tempo de armazenamento do fruto, não diferindo significativamente $(\mathrm{p}<0,05)$ da amostra controle.

Os resultados obtidos na aplicação do cálcio no mamão minimamente processado comprovaram a sua ação na manutenção da firmeza dos frutos (Figura 12), tendo suas médias compreendidas entre 1,88 $\mathrm{N}$ e 4,3N, cerca de $58 \%$ (levando em consideração as médias de todo o período de armazenamento) de diferença das amostras controle e fécula no decorrer no tempo de armazenamento.

A eficiência da aplicação de sais de cálcio na manutenção de frutos foi estudado por Lamikanra \& Watson (2004). Estes pesquisadores avaliaram o efeito do tratamento com lactato de cálcio associado à baixa temperatura $\left(4{ }^{\circ} \mathrm{C}\right)$ no melão minimamente processado. Pedaços imersos em solução de cálcio a $4{ }^{\circ} \mathrm{C}$ apresentaram menor taxa respiratória e menor perda de umidade do que aqueles tratados a $25{ }^{\circ} \mathrm{C}$. Contudo, em estudos realizados por Machado e Alves (2008), tanto o cloreto de cálcio quanto o quelato de cálcio $(0,5$ e $1 \%$ de ambos), mantiveram a firmeza do melão Cantaloupe Hy-Mark minimamente processado por 18 dias. 


\section{Conclusão}

Aplicações de lactato de cálcio a $6 \%$, fécula e, fécula + lactato de cálcio a $6 \%$ preservaram a firmeza do mamão minimamente processado no período de armazenamento. Além disso, isolados ou em associação, contribuíram na conservação da cor do fruto, no controle da acidez titulável e, consequentemente, nos valores de $\mathrm{pH}$. $\mathrm{O}$ estudo revela que a utilização desta técnica, pode ser uma importante alternativa para o aumento da vida útil de mamão minimamente processado.

Trabalhos futuros podem fazer análise sensorial do produto e verificar a existência de correlação entre tais resultados e os resultados das análise físico-químicas.

\section{Referências}

Acevedo, Y. 2008. Eventos fisiológicos asociados a la madurez y calidad de frutos cítricos en Cuba y su relación con los productos transformados de la industria. Instituto de Investigaciones en Fruticultura Tropical, 1-21.

Alam, M. S., Kaur, B., Gupta, K., \& Kumar, S. (2013). Studies on Refrigerated Storage of Minimally Processed Papaya (Carica papaya L.). Agricultural Engineering International: CIGR Journal, 15(14), 275-280. https://cigrjournal.org/index.php/Ejounral/article/view/2611

AOAC - Association of Official Analytical Chemists. (2002). Official methods of analysis of the Association of Official Analytical Chemists. (17a ed.).

Argañose, A. C. S. J., Raposo, M. F. J., Teixeira, P. C. M., \& Morais, A. M. M. B. (2008). Effect of cut-type on quality of Minimally Processed Papaya. Journal of the Science of Food and Agriculture, 88(12), 2050-2060. 10.1002/jsfa.3309

Aslam, H. K. W., Inam-Ur-Raheem, M., Zanoor, T., \& Shahid, M. (2018). Integrated effect of ascorbic acid, citric acid and calcium lactate on quality and shelf-life of fresh-cut papaya cubes. Pakistan Journal of Agricultural Sciences, 55(1), 183-189. 10.21162/PAKJAS/18.6126

Assis, O. B. G., \& Britto, D. (2014). Revisão: Coberturas Comestíveis Protetoras em Frutas: Fundamentos e Aplicações. Brazilian Journal of Food Technology, 17(2), 87-97, 2014. 10.1590/bjft.2014.019

Azzolini, M., Jacomino, A. P., \& Bron, I. U. Índices para avaliar qualidade pós-colheita de goiabas em diferentes estádios de maturação. Pesquisa Agropecuária Brasileira, 39(2), 139-145. 10.1590/S0100-204X2004000200006

Awad, M. (1993). Fisiologia pós-colheita de frutos. Nobel.

Brummell, D. A. (2006). Cell wall disassembly in ripening fruit. Functional Plant Biology, 33, 103-119.

Batista, A. P., \& Borges, C. D. (2013). Métodos de conservação aplicados a melão minimamente processado. Ciencia Rural, 43(5), 915-923. 10.1590/S010384782013005000046

Casas-Forero, N., \& Caez-Ramirez, G. (2011). Cambios morfometricos y de calidad por aplicación de tres Fuentes de calico bajo tratamiento térmico suave en melon (Cucumis melo L.) fresco precortado. Revista Mexicana de Ingeniería Química, 10(3), 431-444. https://www.redalyc.org/pdf/620/62021054009.pdf

Caudal, A. E., Rodrigues, M. Z., Alves, A. I., Araújo, E., Vieira, E. N. R., \& Ramos, A. M. (2016). Adição de Lactato de Cálcio em Manga Minimamente Processada por Impregnação a Vácuo. Anais XXV Congresso Brasileiro de Ciência e Tecnologia de Alimentos, FAURGS, Gramado. http://www.ufrgs.br/sbctars-eventos/xxvcbcta/anais-do-evento

Cavalani, F. C. (2008). Fisiologia do amadurecimento, senescência e comportamento respiratório de goiabas 'Kumagai' e 'Pedro Sato'. (Tese de Doutorado), Universidade de São Paulo, São Paulo, SP.

CEAGESP. (2017). Cartilha de Classificação do Mamão, 25. http://www.ceagesp.gov.br/entrepostos/servicos/produtos/classificacao/.

Cheftel, J., \& Cheftel, H. (1992). Introducción a la bioquímica y tecnología de los alimentos. Zaragoza: Acribia.

Coelho, A. F. S. (2001). Qualidade de alface americana (Lactuca sativa L.) minimamente processada. (Dissertação Mestrado). Faculdade de Farmácia da Universidade Federal de Minas Gerais, Belo Horizonte, Minas Gerais.

Cortez-Veja W. R., Piotrowicz, I. B. B., Prentice, C., \& Borges, C. D. (2013). Conversão de Mamão Minimamente Processado Com Uso de Revestimento Comestível à Base de Goma Xantana, Semina Ciencias Agrárias, 34(4), 1753-1764. 10.5433/1679-0359.2013V34N4P1753

Costa, A. F. S., \& Balbino, J. M. S. (2002). Características da fruta para exportação e normas de qualidade. In: Folegatti, M. I. S., Matsuura, F. C. A. U. Mamão: pós-colheita, Série Frutas do Brasil, 21, 12-18.

Costa, L. C., Costa, R. R., Ribeiro, W. S., Nunes, A. S. E., \& Santos, M. B. H. (2014). Conservação pós-colheita de mamão 'Sunrise Solo' sob atmosfera modificada e permanganato de potássio. Revista Iberoamericana de Tecnología Postcosecha, 15(2), 127-134. 10.1590/S0100-29452011000200040

Couto, H. G. S. A. (2016). Ação do revestimento comestível contendo amido e nisina na conservação de salada de frutas minimamente processadas. (Dissertação de Mestrado). Universidade Federal de Sergipe, São Cristóvão, Sergipe.

De Martin, Z. J., Oliveira, N., Kato, K., Galeb, S. E. A., Silva, S. D., \& Lazzarine, V. (1977). Descascamento mecânico do mamão e processamento do purê asséptico. Coletânea do Instituto de Tecnologia de Alimentos, 8(1), 409-436. 
Draetta, I. S., Shimokami, M., Yokomizo, Y., Fujita, J. T., Menezes, H. C., \& Bleinorith, E. W. (1975). Transformações bioquímicas do mamão (Carica papaya L.) durante a maturação. Coletânea do Instituto de Tecnologia de Alimentos, 6(1), 395-408.

Fennema, O. R., Damodaran, S., Parkin, K. L. (2010). Quimica de Alimentos de Fennema, (4a ed.), Artmed.

Fioravanço, J. C., Paiva, M. C., Carvalho, R. I. N. de., \& Manica, I. (1994). Características do mamão Formosa comercializado em Porto Alegre de outubro/91 a junho/92. Ciência Rural, 24(3), 519-522. http://hdl.handle.net/10183/171258

Food Ingredientes Brasil. (2014). Pectinas: Propriedades e Aplicações. Revista eletrônica, (29). http://revista-fi.com.br.

Fernandes, P. L. O., Aroucha, E. M. M., Souza, P.A., Souza, A. E. D., \& Fernandes, P. L. O. (2010). Qualidade de mamão 'Formosa' produzido no RN e armazenado sob atmosfera passiva. Revista Ciência Agronômica, 41(4), 599-604. 10.1590/S1806-66902010000400012

Garcia, C. C., Canizares, D., Silva, K. S., Darros-Barbosa, R., \& Mauro, M. A. (2012). Utilização de Métodos Combinados Para Obtenção de Mamão Formosa (Carica papaya) Seco. Boletim. Ceppa, 30(2), 185-196. 10.5380/cep.v30i2.30491

Giannoni, J. A. (2004). Irradiação Gama e Armazenamento do Mamão 'Formosa' Minimamente Processado. (Tese de doutorado). Faculdade de Ciências Agronômicas da UNESP. Botucatu, SP.

Lamikanra, O., \& Watson, M. A. (2004). Effect of calcium treatment temperature on fresh-cut cantaloupe melon during storage. Journal of Food Science, 69(9), C468-C472. 10.1111/j.1365-2621.2004.tb10990.x

Lovera, N., Ramallo, L., \& Salvadori, V. (2014). Effect of processing conditions on calcium content, firmness, and color of papaya in syrup. Journal of Food Processing, (1), 1-8. 10.1155/2014/603639

Luna-Guzman, I., Cantwell, M., \& Barret, D. M. (1999). Freshcut cantaloupe: effects of CaCl2 dips and heat treatments on firmness and metabolic activity. Postharvest Biology and Technology, 17, 201-213. https://citeseerx.ist.psu.edu/viewdoc/download?doi=10.1.1.526.3840\&rep=rep1\&type=pdf

Luvielmo, M. M., \& Lamas, S. V. (2012). Revestimentos Comestíveis em Frutas. Estudos Tecnológicos em Engenharia, 8(1), 8-15. 0.4013/ete.2012.81.02

Ma, L., Zhang, M., Bhandari, B., \& Gao, Z. (2017) Recent developments in novel shelf-life extension technologies of fresh-cut fruits and vegetables. Trends in Food Science \& Technology, 64, 23-38. https://doi.org/10.1016/j.tifs.2017.03.005

Machado, F. L. C., Alves, R. E., \& Silva, E. O. (2008). Processamento mínimo do melão "Cantaloupe" com uso de doses de cloreto de cálcio e quelato aminocálcico. Horticultura Brasileira, 26(1), 56-60. 10.1590/S0102-05362008000100011

Miguel, A. C. A., Dias, J. R. P. S., \& Spoto, M. H. F. (2007). Efeito do cloreto de cálcio na qualidade de melancias minimamente processadas. Horticultura Brasileira, 25, 442-446. 10.1590/S0102-05362007000300023

Moretti, C. L. (2007). Manual de Processamento Mínimo de Frutas e Hortaliças, Brasilia: Embrapa Hortaliças. 10.1590/S0102-05362007000300023

Narsaiah, K., Wilson, R. A., Gokul, K., Mandge, H. M., Jha, S. N., Bhadwa, S., Anurag, R. K., Malik, R. K., \& Vij, S. (2015). Effect of bacteriocinincorporated alginate coating on shelf-life of minimally processed papaya (Carica papaya L.). Postharvest Biology and Technology, 100, 212-218. 10.1016/j.postharvbio.2014.10.003

Nunes, A. C. D., Neto, A. F., Nascimento, I. K. S., Oliveira, F. J. V., \& Mesquita, R. V. C. (2017). Armazenamento de mamão 'formosa' revestido à base de fécula de mandioca. Revista de Ciências Agrárias, 40(1), 254-263. 10.19084/RCA16048

Oliveira, M., Abadias, M., Usall, J., \& Torres, R. (2015). Application of modified atmosphere packaging as a safety approach to fresh-cut fruits and vegetables-A review. Trends in Food Science \& Technology, 46(1), 13-26. 10.1016/j.tifs.2015.07.017

Oliveira, T. V., Sasaki, F. F. C., Nepomuceno, C. F., \& Silva, S. O. (2018). Fécula de mandioca, como revestimento, para conservação do mamão. Anais Simpósio do do Papaya Brasileiro, 1-4. http://papayabrasil.com.br/cd/dados/trabalhos/T\%20-\%2036.pdf

Oliveira, M. T. R., Berberte, P. A., Pereira, R. C., Vieira, H. D., \& Carlesso, V. O. (2011). Características biométricas e físico-químicas do fruto, morfologia da semente e da plântula de Averrhoa Carambola L. (oxalidaceae). Revista Brasileira de Sementes, 33(2), 251-260. 10.1590/S0101-31222011000200007

Oliveira, C. M., Coneglian, R. C. C., \& Carmo, M. G. F. (2015). Conservação Pós-Colheita de Tomate Cereja Revestidos Com Película de Fécula de Mandioca. Horticultura Brasileira, 33(4), 471-479.10.1590/S0102-053620150000400011

Pereira, A. S., Shitsuka, D. M., Parreira, F. J. \& Shitsuka, R. (2018). Metodologia da pesquisa científica. [e-book]. Santa Maria. Ed. UAB/NTE/UFSM. https://repositorio.ufsm.br/bitstream/handle/1/15824/Lic_Computacao_Metodologia-Pesquisa-Cientifica.pdf?sequence=1 .

Pinheiro, A. C. M., Vilas Boas, E. V. B., \& Lima, L. C. (2005). Influência do CaCl2 sobre a qualidade pós-colheita do abacaxi cv. Pérola. Ciência e Tecnologia de Alimentos, 25(1), 32-36. 10.1590/S0101-20612005000100006

Revista da Fruta. (2016). Beneficiamento e Pós-Colheita do Mamão. Revista da Fruta. http://revistadafruta.com.br/noticia/beneficiamento-e-pos-colheita-domamao,305383.jhtml

Rivera-Lopez, J., Vazquez-Ortiz, F. A., Ayala-Zavala, J. F., Sotelo-Mundo, R. R., \& Gonzalez-Aguilar, G. A. (2005). Cutting shape and storage temperature affect overall quality of fresh-cut papaya cv. 'Maradol'. Journal of Food Science, 70(7), 482-489. 10.1111/j.1365-2621.2005.tb11496.x

Santana, L. R. R., Matsuura, F. C. U., \& Cardoso, R. L. (2004). Genótipos Melhorados de Mamão (Carica papaya L.): avaliação sensorial e fisico-química dos frutos. Ciência e Tecnologia de Alimentos, 24(2), 217-222. 10.1590/S0101-20612004000200010

Scapin, D. J., Steffen, G. A., Bacarol, M. A., Adams, C. R., \& Klein, C. (2018). Mamão minimamente processado acondicionado em diferentes embalagens. Anuário Pesquisa e Extensão Unoesc São Miguel do Oeste, 3, 16975-16975. https://portalperiodicos.unoesc.edu.br/apeusmo/article/view/16975 
Research, Society and Development, v. 10, n. 11, e373101119508, 2021

(CC BY 4.0) | ISSN 2525-3409 | DOI: http://dx.doi.org/10.33448/rsd-v10i11.19508

SEBRAE. (2016). O Cultivo do mamão e o Mercado de Mamão. https://www.sebrae.com.br

Serpa, M. F. P., Castricini, A., Mitsoubuzi, G. P., Martins, R. N., Batista, M. F., \& Almeida, T. H. (2014). Conservação de Manga com Fécula de Mandioca Preparada com Extrato de Cravo e Canela. Revista Ceres, 61(6), 975-982. 10.1590/0034-737X201461060013

Shinagawa, F. B.(2009). Avaliação das características bioquímicas da polpa de mamão (Carica papaya L.) processada por alta pressão hidrostática. (Dissertação de Mestrado), Universidade Federal do Rio de Janeiro, Rio de Janeiro, RJ. http://186.202.79.107/download/bioquimica-da-polpa-de-mamao.pdf

Silva, A. M., Ambrósio, M., Nascimento, D. S., Albuquerque, A. N., \& Krause, W. (2015). Conservação pós-colheita de banana "maça" com revestimento comestível a asbe de fécula de mandioca. Agrarian Academy, 2(3), 23-34. https://repositorio.ufersa.edu.br/bitstream/prefix/4465/1/JaynyMCF_MONO.pdf

Silva, E. (1981). Estudos da atividade enzimática da polifenoloxidase e da peroxidase em algumas frutas e hortaliças "in natura" e processadas. (Dissertação de Mestrado). Escola Superior de Agricultura de Luiz de Queiroz, Piracicaba, SP.

Silva, W. B., Silva, G. M. C., Silva, L. R., Waldan, W. R., \& Oliveira, J. G. (2015). Tratamento com cloreto de cálcio na pós-colheita retarda o desverdecimento e a perda de firmeza do mamão UENF/Caliman011. Revista Brasileira de Fruticultura, 37(3), 588-599. 10.1590/0100-2945-158/14

Soler, M. P., De Martin, Z. J., Fernades, M. H. C., Mori, E. E. M., \& Ferreira, V. L. P. (1985). Influência dos processos de descascamento na qualidade do purê de mamão da variedade Solo. Boletim do Instituto de Tecnologia de Alimentos, 22(1), 107-123.

Souza, J. F. (2014). Utilização de luz ultravioleta contínua (Uv-C) e luz pulsada para conservação de mangas Cv. Tommy Atkins minimamente processadas. (Tese de Doutorado). Faculdade de Ciências Agrárias e Veterinárias, Unesp, São Paulo, SP. https://repositorio.unesp.br/bitstream/handle/11449/113999/000802313.pdf?sequence=1\&isAllowed=y

Trigo, J. M., Albertini, S., Spoto, M. H. F., Sarmento, S. B. S., Lai Reyes, A. E., \& Sarrriés G. A. (2012). Efeito de revestimentos comestíveis na conservação de mamões minimamente processados. Brazilian Journal of Food Technology, 15(2), 125-133. 10.1590/S1981-67232012005000005

Xisto, A. L. R. P., Breu, C. M. P., Corrêa, A. D., \& Santos, C. D. (2004). Textura de goiabas "Pedro Sato" submetidas à aplicação de cloreto de cálcio. Ciência e Agrotecnologia, 28(1),.113-118.

Werner, E.T., Oliveira Jr., L. F. G., Bona, A. P., Cavati, B., \& Gomes, T. D. U. H. (2009). Efeito do cloreto de cálcio na pós-colheita de goiaba Cortibel. Bragantia, 68(2), 511-518. 10.1590/S0006-87052009000200026

Yao, B.N., Tano, K., Konah, H.K., Bédié, G.K., Oulé, M.K., Koffi-Nevry, R., \& Arul, J. (2014). The role of hydrolases in the loss of firmness and of the changes in sugar content during the postharvest maturation of Carica papaya L. Journal of Food Science and Technology, 51(11), 3309-3316. 